\title{
BMJ Open 'Looking for the needle in the haystack': a qualitative study of the pathway to diagnosis of type 1 diabetes in children
}

\author{
Juliet A Usher-Smith, ${ }^{1}$ Matthew J Thompson, ${ }^{2}$ Fiona M Walter ${ }^{1}$
}

To cite: Usher-Smith JA, Thompson MJ, Walter FM. 'Looking for the needle in the haystack: a qualitative study of the pathway to diagnosis of type 1 diabetes in children. BMJ Open 2013;3:e004068. doi:10.1136/bmjopen-2013004068

- Prepublication history and additional material for this paper is available online. To view these files please visit the journal online (http://dx.doi.org/10.1136/ bmjopen-2013-004068).

Received 18 September 2013 Revised 26 October 2013 Accepted 6 November 2013

CrossMark

${ }^{1}$ The Primary Care Unit, University of Cambridge, Cambridge, UK

${ }^{2}$ Department of Primary Care Health Sciences, University of Oxford, Oxford, UK

Correspondence to Juliet A Usher-Smith; jau20@medschl.cam.ac.uk

\section{ABSTRACT}

Objective: To explore the pathway to diagnosis of type 1 diabetes (T1D) in children from the perspective of the child, family and general practitioner (GP).

Design: Qualitative interview study.

Participants: Parents of children aged 1 month to 16 years diagnosed with new onset T1D within the previous 3 months, children over 6 years diagnosed with new onset T1D within the previous 3 months and GPs who saw those children prior to diagnosis.

Setting: Children and parents were identified and recruited from two hospitals within the East of England.

Results: The parents of 16 children (2-16 years) were interviewed. The total interval from onset of symptoms to diagnosis ranged from 6 to 127 days. The appraisal interval was the longest for almost all children and the diagnostic interval the shortest. Even with some knowledge of T1D, it took many parents several weeks of a complex cyclical and iterative decision-making process and often a physical trigger, such as weight loss, to decide to consult a healthcare professional. By that stage, many had already made or suspected the diagnosis of T1D themselves. Five GPs were interviewed. They felt that the main challenges to diagnosing T1D in children were the rarity of the condition coupled with how well most of the children appeared, and the difficulty in obtaining urine or blood samples from children.

Conclusions: This study highlights the difficulties for parents and GPs in recognising the early symptoms of T1D. It suggests that future interventions should be targeted at parents in the appraisal interval and include the importance of timely presentation to a healthcare professional and the differences between types 1 and 2 diabetes. Primary care physicians should also take parental concerns seriously and do urine dipstick tests during the consultation for children with symptoms of T1D.

\section{INTRODUCTION}

Type 1 diabetes (T1D) is one of the commonest endocrine diseases in children, with an estimated 65000 children worldwide under 15 years developing the disease each year and the global incidence in children continuing to

\section{Strengths and limitations of this study}

- This study is the first exploration of the pathway to diagnosis and presentation of type 1 diabetes in children in primary care and provides a novel perspective of areas in this pathway where future interventions may be targeted.

- The inclusion of children and general practitioners as well as parents provided additional perspectives and triangulation of the findings.

- The use of semistructured interviews allowed an in-depth exploration of the experiences of the participants, but the sample size was small with only 16 of 43 eligible families taking part and the accounts are necessarily retrospective and subject to recall and framing bias.

increase at a rate of $3 \% /$ year. $^{12}$ Despite this, the condition remains rare in primary care: in a large UK General Practice, a child with new onset T1D will be seen only about once every 2 years. ${ }^{3}$ Differentiating the rare child with T1D from the large number with minor undifferentiated illness is challenging for families and primary care physicians: up to $86 \%$ of children are not diagnosed at the first encounter, ${ }^{4-8}$ and worldwide up to $80 \%$ present in diabetic ketoacidosis (DKA), ${ }^{9}$ which has immediate life-threatening complications and is associated with poorer long-term diabetic control. ${ }^{10-12}$

Finding ways to increase symptom awareness and reduce the number of children presenting with DKA at diagnosis has recently become an area of increasing worldwide interest: the International Diabetes Federation has been running the 'Defeat DKA and Save Lives' programme since 2007 and provides DKA awareness posters in multiple languages on the internet ${ }^{13}$; and campaigns similar to the community intervention in Parma in Italy where the frequency of DKA at diagnosis fell from $78 \%$ to $12.5 \%{ }^{14}$ have been launched worldwide, including the UK, ${ }^{15}$ Kuwait, ${ }^{16}$ Australia ${ }^{17}$ and the USA. ${ }^{18}$ 
Central to the success of these and any future initiatives is understanding the pathway to diagnosis. Our recent systematic review ${ }^{19}$ confirmed that a significant number of children experience delay in diagnosis or misdiagnosis and found that the mean duration of symptoms for children who presented with or without DKA was over 2 weeks. However, although this and other studies ${ }^{4-8}$ highlight the difficulties in making the diagnosis, none have explored the reasons behind this period of delay between symptom onset and diagnosis. The aim of this study was to explore this pathway to diagnosis from the perspective of the child, their family and the general practitioner (GP). Using semistructured interviews, it provides the first in-depth description of the diagnostic pathway of T1D in children and exploration of the symptom appraisal, help-seeking and diagnostic stages.

\section{METHODS}

Design

Semistructured face-to-face in-depth interviews were conducted with children 6 years and over and the parent (s)/guardian(s)/step-parents (hereafter referred to as parents) of children aged 1 month to 16 years diagnosed with T1D within the previous 3 months. We also conducted semistructured telephone interviews with the GP who saw the child prior to diagnosis.

\section{Setting}

Children and parents were identified and recruited via the paediatric diabetes specialist nurses at two hospitals within the East of England. Together they serve a population of approximately 675000 and see between 30 and 45 children with newly diagnosed T1D each year. Parents, children and GPs were given separate written information about the study and had the opportunity to ask questions before making a decision to participate. Children between the ages of 6 and 16 years gave their assent.

\section{Recruitment}

Parents of all children aged 1 month to 16 years diagnosed with new onset T1D at the two participating hospitals were eligible for inclusion unless their clinical team felt that they were not suitable on clinical grounds (when the invitation would adversely affect the care the child received, either through a breakdown in relationships between the family and the clinical team or due to specific clinical circumstances). Children aged 6-16 years were also eligible for inclusion in the study themselves. Children and parents were initially identified by the paediatric diabetes clinical teams which gave them an information pack about the study with the study team contact details. Following consent from the parents, the GP who had seen each child prior to diagnosis was invited by letter.

\section{Participants}

Forty-three children were diagnosed with T1D in the two hospitals during the study period (1 January 2012-28
February 2013). Of those: 32 were invited to take part in the study; one family was not invited as they did not speak English; one family was not invited on clinical grounds as the parents were not accepting the diagnosis of diabetes and so the relationships were already strained between the family and the clinical team and the other nine were missed during follow-up. Twenty responded to the initial invitation and 16 agreed to take part. Of the 16 children included in the study, 12 saw a GP at their registered surgery prior to diagnosis. One saw a nurse and three contacted the Out Of Hours service and were directed from there to hospital. One family was interviewed 3 months after diagnosis, so it was not possible to also invite and interview the GP within 3 months of diagnosis. Of the remaining 11 GPs who were invited to take part, 5 agreed to be interviewed.

\section{Interviews}

The children and their parents were invited to take part within 3 months of diagnosis. Children over 6 years were given the opportunity to be interviewed as well as their parents; they were asked whether they would prefer the interview to be conducted with or without their parents. Parents of children less than 6 years old were invited to bring their child to the interview if they felt that would be appropriate. Interviews were all performed by one researcher (JAU-S) and continued until saturation of data.

Each interview was semistructured and used an interview schedule informed from the literature and previous interviews of young people with new onset T1D available online at Youth Health Talk. ${ }^{20}$ The interview schedule (see online supplementary appendix 1) covered the entire process from recognition of initial symptoms through to diagnosis and focused on the appraisal of symptoms, the decision-making processes about seeking medical help, their experiences of the diagnostic process, and the role of family members, friends and information sources. They all began with an open question: "Thinking back, can you tell me what happened from first becoming aware that something wasn't quite right until your child was given the diagnosis of diabetes?" to allow parents and/or children the opportunity to describe the story of the diagnosis in their own words. A calendar-landmarking technique ${ }^{21}$ was then used to establish the timing and details of events which had occurred during that time and symptoms and events explored in depth.

At the end of each interview, parents completed a short questionnaire to provide demographic information about the child and family.

Interviews with GPs were carried out by telephone by the same researcher (JAU-S) using an interview schedule (see online supplementary appendix 2) covering the specific diagnostic pathway of the child and, more generally, issues the GPs experienced with the diagnosis of diabetes and other serious conditions in children in primary care. 


\section{Analysis}

Interviews were transcribed verbatim and read by at least two researchers (JAU-S+FMW/MJT). They were then analysed using thematic analysis ${ }^{22}$ with the aid of NVivo software (QSR International, V.9). The analysis was an iterative process starting near the beginning of data collection, with final themes agreed through a series of meetings involving all three researchers.

During this analysis process, Walter et al's model of Pathways to Treatment ${ }^{23}{ }^{24}$ (figure 1) was used to provide a theoretic model of the different intervals that occur along the pathway to diagnosis and treatment in order to accurately assess the time intervals. As described in the model, the pathway to diagnosis was divided into two intervals prior to presentation to healthcare about a symptom (the appraisal interval from the onset of symptoms to perceiving a reason to discuss symptoms with a healthcare professional, and the help-seeking interval from that decision until presentation to a healthcare professional), and then the diagnostic interval from first presentation to a healthcare professional until diagnosis. Intervals were calculated from the interviews. Where uncertainty about the transition between the different intervals existed, the transcripts were reviewed by the research team to reach consensus.

Throughout the text, children are referred to by study number (1-16) with quotations prefixed with the person speaking, $\mathrm{M}$ for mother or $\mathrm{F}$ for father/stepfather/ guardian. GPs are referred to by study letter (A-E).

\section{RESULTS}

The characteristics of the 16 children included in the study compared with the children who were invited but did not take part and those who were eligible but not invited are shown in table 1 . The included children were younger and less likely to have had DKA at diagnosis.

One interview with parents took place in the Primary Care Unit in Cambridge while all other parents chose to be interviewed at home. Mothers were present in all interviews with fathers, stepfathers or guardians present in 10 cases and children on nine occasions (table 2). The average duration of interviews was $30 \mathrm{~min}$, although it was not uncommon to have interruptions throughout from either children or pets.

The characteristics, intervals along the diagnostic pathway, common symptoms and diagnostic details of the children are shown in table 2 . The children included boys and girls ranging in age from 2 to 14 years with two presenting in DKA. The interval from onset of symptoms to diagnosis ranged from 6 to 127 days (mean $44 \pm 37$ days) with the appraisal interval being the longest in almost all cases. All experienced at least one of the key symptoms of diabetes (polydipsia, polyuria, lethargy or weight loss) and most were diagnosed at their first consultation with a healthcare professional (table 2).

The families had a range of sociodemographic backgrounds. The majority had a combined income of $£ 30000-£ 50000$ /annum but this ranged from $£ 10000$ $£ 20000$ to more than $£ 100000$. Most were white English with two Polish and one mixed British and Iranian. Overall, the parents were well educated with over half having either a University or Graduate degree, but the group also included parents with less education and for whom English was a second language. Four of the families had personal experience of diabetes, three with a family history of T1D and one who was medically trained.

In all cases, parents gave very detailed accounts of the events leading up to their child's diagnosis. Many had made contemporaneous records or diary entries which they referred back to, with several marking the date of diagnosis as 'D-day'. Even without these, parents were able to recall specific dates, events and conversations in detail. The children had less clear memories of the events, and in most cases their contributions to the interviews were limited to agreeing with their parents or answering questions with simple 'yes' or 'no' answers.
Figure 1 Model of Pathways to Treatment (reproduced with permission from Walter et al, $\left.2011^{23}\right)$.

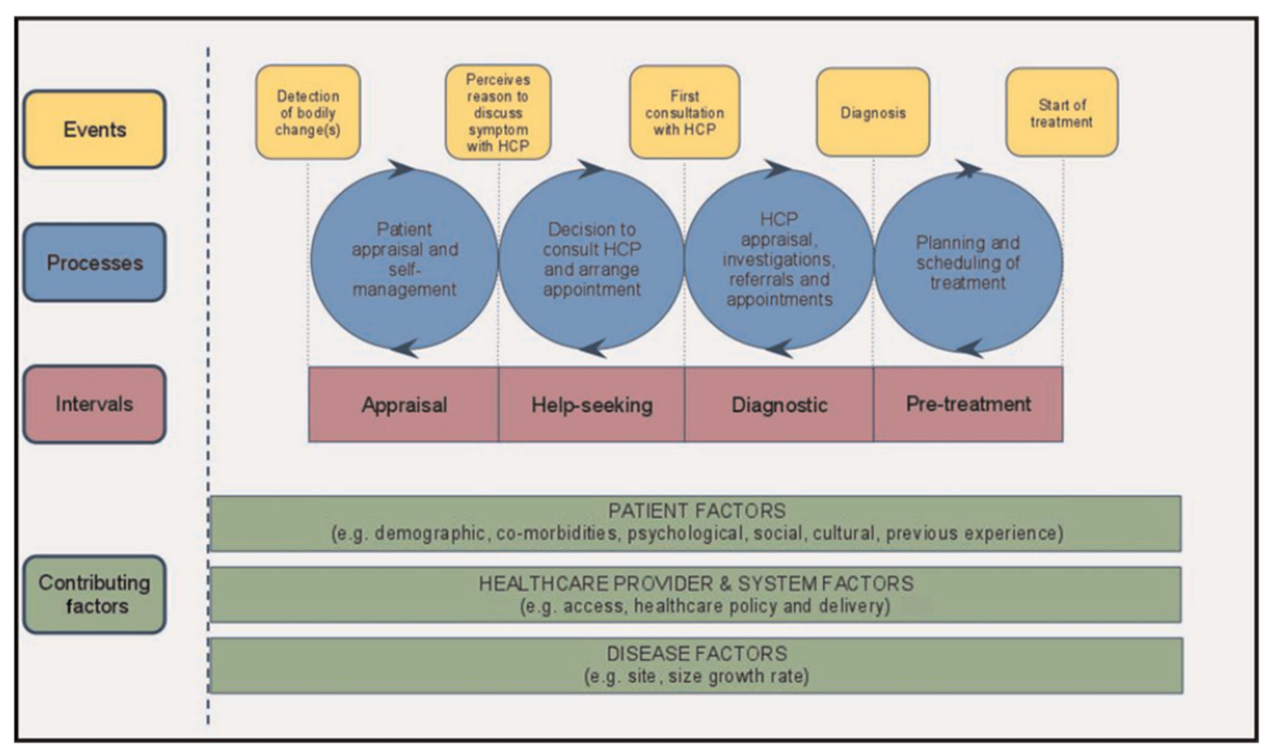


Table 1 Characteristics of children included in the study compared with those who were invited but did not take part and those who were eligible but not invited

\begin{tabular}{llll}
\hline & Included in study $(\mathbf{n = 1 6 )}$ & Invited but did not take part $(\mathbf{n = 1 6 )}$ & Eligible but not invited $(\mathbf{n = 1 1})$ \\
\hline Age & & & 3 \\
Less than 6 years & 6 & 2 & 3 \\
6-8 years & 4 & 3 & 3 \\
9-11 years & 3 & 3 & 2 \\
12-16 years & 3 & 8 & $8.5 \pm 4.1$ \\
Mean \pm SD & $7.3 \pm 4.1$ & $10.1 \pm 3.5$ & $(3-16)$ \\
Median (range) & $6.5(2-15)$ & $11(4-14)$ & $4(36 \%)$ \\
Gender & & & $7(64 \%)$ \\
Male & $9(56 \%)$ & $8(50 \%)$ & $3(27 \%)$ \\
Female & $7(44 \%)$ & $8(50 \%)$ & $8(73 \%)$ \\
DKA & & & \\
Yes & $2(13 \%)$ & $4(25 \%)$ & \\
No & $14(87 \%)$ & $12(75 \%)$ & \\
\hline DKA, diabetic ketoacidosis. & &
\end{tabular}

GPs referred to their consultation records and all GP accounts agreed completely with those given by the parents.

The analysis focused on the main themes within the appraisal, help-seeking and diagnostic intervals and then the influence of knowledge and experience of diabetes across the complete pathway to diagnosis. The main emerging themes within each are discussed below.

\section{Appraisal interval}

The appraisal interval was the longest interval for almost all families and one in which the parents described a complex process of recognition and appraisal of symptoms, with parents continually reviewing the symptoms and their interpretations.

\section{Subtlety of symptoms}

Many parents described the subtlety of the symptoms and the difficulty they had in recognising them at the time.

But then, like you say, I mean, now it's obvious, isn't it, now, the drinking, the going to the toilet, the sickness. It was just...it's obvious isn't it, but it wasn't at the time, you know. M8

No, it, just little bits here and little bits there, it wasn't anything you could connect. M9

Difficulty in recognising the symptoms was also evident in the children's accounts with several not noticing them until either their parents mentioned them or after the diagnosis.

I didn't think it was anything different 'til my mum said some stuff I started thinking. C16

I didn't really realise it because I just felt probably tired for a long time. I just felt like, after the first time I had my insulin I felt more awake than I did before. C15

\section{Alternative explanations for symptoms}

Almost all parents initially found alternative explanations for the early symptoms. These included a 'phase' the children might be going through, puberty, being a child or teenager, a growth spurt, separation anxiety, hot weather or school. Illustrative examples for each of these are shown in table 3 .

In general, children were less concerned with finding explanations for their symptoms and more likely to just accept them.

I just felt hungry, I didn't know why, I just needed more food. C16

There was evidence, however, that some children found alternative explanations themselves.

I was just thinking that I was doing a lot of exercise and I was just getting thirsty. C13

\section{Nature of symptoms}

The nature of symptoms played a key role in the appraisal interval. Symptoms that were intermittent, not unusual for the child or not making the child 'unwell' did not cause concern to parents, while almost all parents described becoming concerned when the symptoms were different or unusual for their child or when there were physical signs such as weight loss or vomiting that could not easily be attributed to behaviour, or when symptoms started to interfere with daily life (table 4).

Whether the symptoms interfered with daily life was also a key factor in how the children responded to their symptoms. Symptoms such as increased appetite and thirst did not generally interfere with their lives and did not cause concern. Instead, they thought it was 'great because I could eat more' or 'quite funny'. In contrast, urinary symptoms and lethargy did appear to impact on their lives and, as a result, led to concern. 


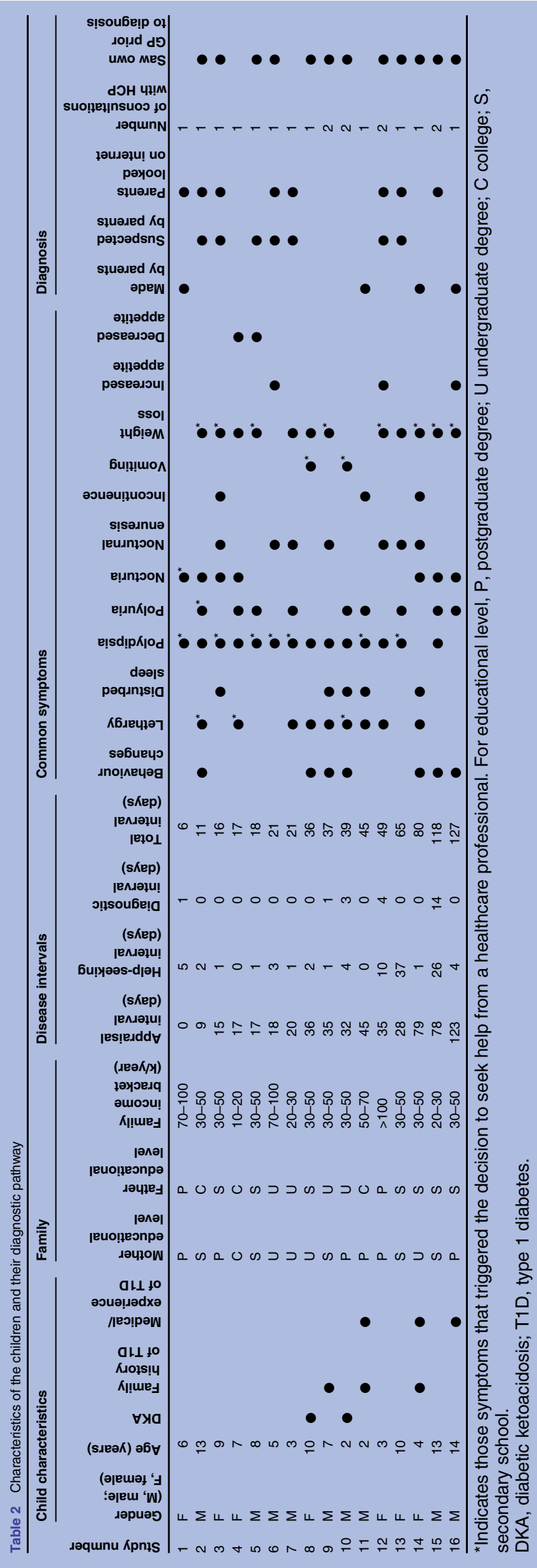

So I woke up but it was just I didn't have time to sort of go, it didn't let me stop...that's why I got worried because it was just like normally just can wait a minute and get there, but it was just I couldn't wait. C13

Well I was a bit tired and after three days I like didn't really want to eat anything and I was only in bed, I would do nothing, just bed...It wasn't good. C4

\section{Influence of other family members and social network}

In most cases, both parents appeared to be in agreement throughout the appraisal process. In the cases where there was conflict, it was consistently the mothers who were more concerned than the fathers.

My husband thought I was being silly, you know, we've got no history in our family, nothing so there wasn't any reason to suspect really and to look at her you would never think, she was fine in herself, the only thing was she was drinking more and going to the toilet. M1

It was round about that time his mother was seeing [him losing weight], and we was not arguing but I'm saying no, he's fit enough. F9

Apart from their husband or partner, most mothers discussed their concerns with their mother, friends or work colleagues before making an appointment to see a healthcare professional. These conversations had a number of influences: reinforcing their own explanations of the symptoms; reinforcing their concerns and decision to seek help; prompting concern and a decision to seek help or challenging their concerns and so delay help-seeking. Notably, grandmothers seemed to be particularly important in reinforcing mothers' concerns. Illustrative quotes for each of these are shown in box 1 .

In most cases where the views of others were in conflict with the mothers' own views, the mothers ultimately allowed their own concerns to override the comments of others and chose to seek help.

I remember another friend at the school gate was just, sort of, saying, "Oh, my daughter was thirsty a lot and I didn't really think that much of it and I'm sure it'll be nothing," sort of thing. But I was, like, "Well, I'm just going to get him checked out anyway." M6

So I was still saying to family about me worries and they were still saying puberty and friends, oh it's puberty, you're worrying yourself and, you know, don't worry about it, I wouldn't worry. M15

The time it took for them to do this appeared to relate to the number of people providing alternative views; when it was just one friend, the mothers could quite easily follow their own concerns while multiple members of the family had a greater influence.

Notably, none of the children, even those who were worried about their symptoms, mentioned anything to their parents before they were diagnosed with one child 
Table 3 Examples of parents' alternative explanations for symptoms

\begin{tabular}{|c|c|}
\hline A 'phase' & $\begin{array}{l}\text { But there wasn't particularly anything medical that I was thinking about at that point, I thought it } \\
\text { [wetting the bed at night] was just a phase she was going through that my other children hadn't gone } \\
\text { through. M12 } \\
\text { And he had started drinking a lot more, but he went through a phase of drinking a lot at one stage you } \\
\text { know and it was about that age and I thought oh you know they're just, he's just going through that } \\
\text { phase. M11 }\end{array}$ \\
\hline Puberty & $\begin{array}{l}\text { We were asking him all questions, are you being bullied at school, is there anything you want to tell us, } \\
\text { is something happening because he'd just gone really thin and then I was speaking to members of } \\
\text { family and friends about it and everybody was saying it's probably puberty because he's thirteen, it's } \\
\text { just puberty, he's getting taller. M15 } \\
\text { Something [her mother] had said, you know, at } 11 \text { she started her period, maybe she thought it was } \\
\text { the same for [the child], and you know, maybe that's why, sort of hormones changing, she thought } \\
\text { that's why she's so temperamental, you know. F8 }\end{array}$ \\
\hline $\begin{array}{l}\text { 'Being a child/ } \\
\text { teenager' }\end{array}$ & $\begin{array}{l}\text { So actually there is quite a lot which is related to behaviour, which I just put down to her being four and } \\
\text { a little bit short tempered and, you know, "I don't like 'cos my brother's getting too much attention," } \\
\text { M14 } \\
\text { Initially [we] just thought it was his [being a ] teenager, starting a new school, sort of mixing with } \\
\text { different people, so we didn't really take an awful lot of notice. M2 }\end{array}$ \\
\hline Growth spurt & $\begin{array}{l}\text { I was thinking "oh well a lot of people have said the children are shooting up that way and obviously } \\
\text { they become thinner for a while until it all evens its way out", so I was sort of rationalising that, thinking } \\
\text { "oh that will just be a growth spurt". M13 } \\
\text { She looked skinny, didn't she, and we assumed that she'd.....gone tall, you know how they do. M3 }\end{array}$ \\
\hline Separation anxiety & $\begin{array}{l}\text { I was aware that he was drinking more but because of all the shenanigans about the mugs, again I just } \\
\text { thought you're just playing, you're playing me here because his dad's away. M10 }\end{array}$ \\
\hline Hot weather & $\begin{array}{l}\text { She drank an awful lot that week, yeah, but that week was very, very hot as well and it coincided with } \\
\text { some very hot weather here. So again, it was something that was odd but I wasn't unduly sort of } \\
\text { concerned at that point. M12 } \\
\text { It [had] been nice weather so he spend time in the garden... Yeah, to play around and we thought, } \\
\text { okay, sometimes maybe he needs some more sleep to get more energy for rest of the day... F7 }\end{array}$ \\
\hline School & $\begin{array}{l}\text { But I thought "Oh it's end of term, we're all tired quite frankly, we're all ready for the summer holiday, } \\
\text { I expect Sarah's tired as well" M12 } \\
\text { I guess again we just put it down to she's just started school, she's getting used to the routine and } \\
\text { that's what we thought it was. M14 }\end{array}$ \\
\hline
\end{tabular}

even admitting that he had been worried but kept saying there was nothing wrong each time his parents mentioned taking him to the doctor.

\section{Sources of information}

Most parents looked on the internet for explanations for the symptoms (see table 2) and this either raised or confirmed concerns about diabetes.

That night I just Googled symptoms like drinking more and toilet, and diabetes came up. I mean if I hadn't looked on the internet I wouldn't have thought about diabetes...until putting in the symptoms I wouldn't have clicked that it was diabetes. M1

The biggest symptom I've ever been told about is the constant need to urinate, and because he was going so much that's probably what prompted me to look and see whether there was any other symptoms that could have been....and the symptoms he had started to tally up with diabetes. M2

No parents sought information from any other written sources.

\section{Help-seeking interval}

The help-seeking interval ranged from 0 to 37 days with most children seeing a healthcare professional within 5 days of the parents perceiving the need to seek help. Reasons for waiting before seeking help included concern about going with non-specific symptoms and wasting the GP's time, waiting to 'see how it goes', fear of the diagnosis and unawareness of the importance of a timely diagnosis (box 2). There was no evidence that particular family events or social issues influenced this process. The lack of awareness of the potential seriousness of the condition was, however, particularly evident among parents who suspected diabetes but whose children still appeared well. A number continued to wait several days after considering the diagnosis before seeking help and this decision appeared to be related to their understanding of diabetes being based on knowledge of type 2 diabetes.

\section{Ease of getting an appointment with GP}

Once parents had made the decision to take their child to a GP, all who requested an emergency appointment 
Table 4 Features of symptoms that did and did not cause concern to parents

\begin{tabular}{|c|c|}
\hline \multicolumn{2}{|c|}{ Features of symptoms that did not cause concern to parents } \\
\hline Intermittent & $\begin{array}{l}\text { It wasn't like she was constantly asleep, you know, sometimes she'd just have like a little cat nap } \\
\text { almost you know, and then she'd be back bounding around again, you know, so it wasn't that } \\
\text { worrying. F8 } \\
\text { 'That [increased drinking] was really sporadic. I mean he was only obviously drinking more on } \\
\text { that week that he was diagnosed. M11 }\end{array}$ \\
\hline Not unusual & $\begin{array}{l}\text { I mean, he has always been a bit, sort of, he gets, he was getting tired but he can be quite like } \\
\text { that anyway, so that didn't really ring too many alarm bells, to be honest. M6 }\end{array}$ \\
\hline $\begin{array}{l}\text { Not making the child } \\
\text { 'unwell' }\end{array}$ & $\begin{array}{l}\text { He hadn't changed in any way, he was still managing to play football and you know, and there } \\
\text { was no ill effects of him. M16 } \\
\text { To look at her you would never think, she was fine in herself, the only thing was she was drinking } \\
\text { more and going to the toilet. M1 }\end{array}$ \\
\hline \multicolumn{2}{|c|}{ Features of symptoms that caused concern to parents } \\
\hline $\begin{array}{l}\text { Different or unusual } \\
\text { for the child }\end{array}$ & $\begin{array}{l}\text { It was not usual for her to drink that, you know, she never drinks water at night, she never gets } \\
\text { up in the night so those were the triggers to me saying that there was something wrong.. M1 } \\
\text { But when he started wetting his bed every night I was sure something is wrong because it's } \\
\text { unusual. M7 }\end{array}$ \\
\hline Physical & $\begin{array}{l}\text { It was only that last two weeks when he actually took his top off in front of me and then I } \\
\text { panicked, I did, get him to the hospital 'cos he's, you know, his actual shoulders were poking out } \\
\text { and he had this like translucent look about him F9 } \\
\text { Yeah, that's [vomiting] what really, more than anything, started raising the alarm bells, you know. } \\
\text { F8 }\end{array}$ \\
\hline Interfering with daily life & $\begin{array}{l}\text { Um, because I think that drinking the water had increased so much it was getting to be } \\
\text { ridiculous, you know, life was revolving around her needing a drink. M13 } \\
\text { For that following week he done nothing but drink, I mean he could drink a fish out of water, I tell } \\
\text { you, couldn't you? Just permanently drinking one drink after another and he couldn't get that } \\
\text { thirst away. M5 }\end{array}$ \\
\hline
\end{tabular}

were offered one the same day (one at the walk-in centre because the GP surgery had no appointments). Only two families described difficulty in getting an appointment. In one case, an appointment arranged for 5 days later was rearranged to an emergency appointment, and in the other the child was initially seen by a nurse and then had to wait until the afternoon to see the doctor.

One parent had to wait 20 days for an appointment but was quite happy with that and knew that she could have got an emergency appointment the same day if she had wanted it:

It was about three weeks before the appointment which is the normal timescale for getting an appointment down at our surgery. Which I was quite pleased about in a way...I was probably thinking "oh right, we'll get Christmas out of the way and then, you know, there's nothing wrong with her...I suppose I could have got an emergency appointment but I didn't'. M13

\section{Diagnostic interval}

The diagnostic interval was the shortest interval for all children with the majority diagnosed on the same day as their first encounter with a healthcare professional. In four cases, the parents had already made the diagnosis: one mother had bought glucose testing strips from the pharmacy; one mother was a nurse and had checked the child's urine at work and the other two had diabetes themselves and had checked the child's blood glucose at home. Parents suspected diabetes in a further seven cases after researching their child's symptoms on the internet or, in one case, discussing them with the child's grandmother who was a nurse.

Four children had more than one encounter prior to diagnosis. In two cases, this was because they were unable to provide a urine sample, so parents were asked to return it to the GP surgery at a later date. In the other two cases, the parents had spoken to a health visitor in the days leading up to the diagnosis. In one case, the health visitor had suggested that the mother take the child to the GP for a urine test and the child was diagnosed at that first appointment with the GP, and in the second the health visitor reinforced the mother's alternative explanations of his behaviour:

Well she basically said "you know he's two and a half and toddlers are moody and you know, I wouldn't really worry about his behaviour because they're all the same", and she said "you know, keep an eye on the drinking but just go up a size in nappy, it might be that your nappies are too thin." M10

\section{Parents feeling they needed to push for investigations}

Although the diagnosis was made at the first appointment in the majority of cases, many parents felt that they had to push quite hard for the GP to test the urine and that their GP was surprised at the diagnosis: 
Box 1 Illustrative quotations of the influences of comments from extended family and friends

To reinforce their own alternative explanations of the symptoms I think I probably talked to some friends as well about it and whether their children had, once they'd been dry in the night, then perhaps you know, started wetting the bed again and some of them said yes, that did happen so I thought okay, maybe she's just going through that phase. M12

To reinforce their concerns and decision to seek help As I say, it was almost instant weight loss in his face was where we noticed it, he just went really gaunt, and my Mum also commented on that that night. M2

So, Mum noticed it then, and then I said to her we'd noticed that, you know, talking like you do to your Mum, did she think there was anything, and Mum's answer, as always is, "If you're not happy, go to the doctor's and get it checked out". If you think there's something wrong, don't waste any time, so we didn't, did we. Not that I, we needed her to say, "You should take her," but, you know, it makes you feel a bit better about going. M3

To prompt concern and a decision to seek help My Mum [and] me husband would say "I wonder if he's got diabetes or something". My Mum said "Well I think he has", see my Mum's big in the medical profession, she said "Sarah, I think he's got diabetes, I think" she said. M5

To challenge their concerns and in doing so delay help-seeking And then I was speaking to members of family and friends about it and everybody was saying it's probably puberty because he's thirteen, it's just puberty, he's getting taller and [my partner] said as well, it probably is, he's that age where he's getting taller so I were like, yeah, yeah, everybody's probably right, it's nowt. M15

[The GP said] you could just drop a urine sample off if you wanted to tomorrow, and we'll send it off, and hear back in a week or so." But I sort of said, "But I think we need to get the sample from him now and do the test now." M6

So he wasn't particularly convinced that [diabetes] was what it was...and then he was like, "Well I'll test her wee then," and then he came back some $10 \mathrm{~min}$ later and said, "It is."...You could have knocked him down with a feather, I think. He looked completely gobsmacked...M3

\section{Challenges for GPs diagnosing T1D in children}

The GPs felt that the main challenges to diagnosing T1D in children were the rarity of the condition and the difficulty in obtaining urine samples or blood glucose measurements from children. One likened the diagnosis to finding the needle in the haystack with others describing how the rarity of the condition and the subtle and vague symptoms meant it could easily be attributed to more common conditions:

I suppose the fundamental one is that you have to think of it, that it's relatively unexpected. New diagnoses of diabetes in infants are a relatively rare phenomenon,
Box 2 Reasons parents waited before booking an appointment with a healthcare professional

Concern about going with non-specific symptoms and wasting the general practitioner's time

Because we were umm-ing and ah-ing, we didn't want to waste the doctor's time or get sent away with, you know, "It's a virus." M3

I thought I didn't want to be paranoid going to the doctor and saying without, you know, without kind of having some proof in effect that I'm not being a paranoid mum. M1

Waiting to 'see how it goes'

And then on the Friday afternoon he basically slept all afternoon so I thought all right he's definitely coming down with something, umm'ed and ahh'ed about calling the doctors and I thought oh it's Friday l'll see how it goes over the weekend M10

I think by Friday night he was mentioning it again and I thought, "Ooh, I'll see how it goes over the weekend." M6

Fear of the diagnosis

I suppose I could have got an emergency appointment but I didn't. Maybe I prolonged it myself because I was thinking the worst in the back of my mind, as a mother's sort of, you know, intuition type thing. M13

I think the fact not wanting him to have it and knowing deep down he probably had it but not wanting him to have it, that was the thing [that made me wait] I think. M16

Unawareness of the importance of timeliness of diagnosis

Anyone who's not connected with Type 1 doesn't understand the seriousness of it and they just think about, "Oh well, you'll just have to have a bit of insulin and you just get on with life." So I think, you know, you associate it, I mean, more with the Type 2, people think "Oh well, loads of people have that, it's quite common." M6

I just thought oh you know, because you hear about people with diabetes, you say "Oh the first sign is a lot of drinking and a lot of urinating". I thought what if he has got a bit of diabetes? M5

whereas coughs and colds are very common, so you're looking for the needle in the haystack. GPA

It's very rare and so we don't see a lot of it...so because it's rare it might not come to mind when you're seeing a child. I mean children, the sort of symptoms...the symptoms are very subtle. GPE

After suspecting the condition, most GPs felt urine testing and measurement of blood glucose were difficult:

I think urine sample testing in infants is difficult because it's a hoo-ha trying to get a urine sample, and sometimes just the pressure of work in general practice makes it difficult to get a urine sample... The temptation to say 'I think this will get better on its own' instead of doing the test is strong because most stuff does get better on its own. GPA

They're young children and you don't want to sort of do unnecessary invasive procedures, blood tests, skin prick tests, those sort of things if it's going to cause them a lot of distress and you're not going to be picking it up.... I 
wouldn't want to do a BM on every child I saw who was unwell because I think I'd end up, you know, with a room full of screaming children waiting to see me. GPD

One GP had the opposite view and described using urine testing as a means to get control of consultations:

One of the diverting things I thought was that I ought to test his urine. So I thought if we did that, that would give the child a chance to go out of the room and come back in again. GPB

The GPs also identified a number of factors that make diagnosing serious conditions in children difficult in general including: the fact that they see a large number of children, most of whom have self-limiting illness; the difficulties with getting a history, developing rapport with children and doing investigations; and concern about imparting worry and anxiety to parents and balancing messages about health-seeking behaviour.

\section{Role of prior knowledge or experience of diabetes}

Half the parents described being aware of the symptoms of diabetes prior to their child being diagnosed. In some cases, it was clear that this knowledge or experience prompted earlier help-seeking and diagnosis:

I remember a billboard on my way to work, it sort of said symptoms of diabetes, thirst, going to the toilet lots and tired. It just stuck in my mind and I remember that, and so that's what made me think, "Yes, yes, yes." M6

In others, however, the symptoms and presentation of diabetes were not as they had expected and this mismatch with their prior beliefs appeared to delay help-seeking:

I guess I'd always known that it was a possibility that she and my son might develop it [T1D] at some point but because my Dad was diagnosed at 13 and I was diagnosed at 13 I thought, if it's gonna happen she's gonna be a teenager. M14

I think it [diabetes] was just somewhere in my mind but, you know, she wasn't poorly so I kind of thought "well she seems like a well child that drinks a lot really". You expect to see a sort of poorly child don't you, or some other sort of symptoms that were more obvious? M13

The subtlety of many of the symptoms also meant that putting them together and recognising them as diabetes was difficult even for parents with T1D themselves:

All these little things that can be put down to other stuff and even when you know about it [diabetes] it still takes something like that [weight loss] for you to put it all together.... But now when we look back on it we can see all these different things that were signs that it was type one diabetes which we hadn't picked up on because we just hadn't put it all together. M14
Previous experience of presentation of T1D also appeared to frame the GPs views on presentation and subsequent decision-making. In several cases, the GPs' only experience of T1D in children came from experience in hospitals and, as a result, several GPs described how they viewed T1D as a medical emergency and would expect children to present acutely unwell:

No, I think this is the first one...well, as a junior doctor in hospital, yes, and as a medical student, yes, I saw new diabetics, and generally the Type 1's when they were newly-diagnosed, the ones that I'd see were ketotic. So they came in with DKA. GPD

I would say that they tend to present pretty ill, because it's going to be a Type 1 diabetes and they become ill pretty rapidly. So yeah, I regard new diabetes as a medical emergency. GPA

In some cases, this led to a mismatch between the GP's beliefs around the presentation of T1D and the child in front of them:

I suppose the thing that surprised me in a way was the fact that he didn't look any different to a lot of children that you see who, you know, just recovering from a cold or a cough or that kind of thing. GPC

Conversely, one GP described how he had seen a number of children in the past with similar presentations and this had made him more aware of the condition and changed his practice:

I've sent in three newly diagnosed otherwise fit children who have first diagnosis diabetes. And they've all tended to be a slightly, well a similar sort of vein and so I have a sort of heightened suspicion now, so I do urines, you know, frequently if there's anything that doesn't quite fit or a concern that it may be a possibility. GPB

\section{DISCUSSION}

\section{Principal findings}

This study provides the first study exploring the pathway to diagnosis of T1D in children and validates the application of the model of Pathways to Treatment in a childhood and non-cancer condition. It shows that most of the total diagnostic interval for T1D in children is the appraisal interval. The early symptoms are subtle and, even with some knowledge of T1D, it took many parents several weeks of a complex cyclical and iterative decision-making process and often a physical trigger, such as weight loss or vomiting, to decide to consult a healthcare professional. Once they had made the decision to seek help, however, the help-seeking and diagnostic intervals were short, with almost all children seen immediately and diagnoses were mostly prompt and managed appropriately. Parents continued to play a key role during the diagnostic interval, however, with many having already made or suspected the diagnosis themselves by the time of the first consultation 
with healthcare professionals, and several feeling they had to push hard for GPs to take their concerns seriously. The GPs felt that the main challenges to diagnosing T1D in children were the rarity of the condition and the difficulty in obtaining urine samples or blood glucose measurements from children. They also demonstrated how previous experience of conditions frames future practice and the difficulties in translating knowledge of disease presentations from secondary care experience to primary care.

\section{Strengths and weaknesses}

We believe this is the first study to examine the pathway to diagnosis of T1D in children and to provide a novel perspective of the areas in this pathway where future interventions may be targeted. We used semistructured interviews soon after diagnosis to allow participants to speak freely about the period leading up to the diagnosis and also framed our analysis using a theoretical model. The sample size was small, but data saturation for the parents was reached before the total sample had been interviewed and, together with the similarity among key characteristics between children included and not included in the study, suggests that our findings are robust and representative of children diagnosed with T1D in this region.

The main weakness is that the interviews are necessarily retrospective and subject to recall and framing bias. As a result, the parent and child accounts cannot be regarded as an exact description of what happened. Rather, they are narratives that allowed the parents to describe their experiences and reflect a post hoc rationalisation of events framed by their subsequent encounters with healthcare professionals and increased knowledge since the diagnosis. In the cases where GPs were interviewed, however, the parents' descriptions of symptoms, events and dates agreed completely with those of the GP records. A further limitation was the difficulty in capturing children's insights, and we were only able to interview a small proportion of GPs that may not have achieved saturation in the GP perspective of the diagnostic processes. The inclusion of children and GPs in the study, however, provided triangulation to the findings of the parents and adds a different perspective to the pathway.

\section{Comparison with existing literature}

The total duration of symptoms prior to diagnosis ranged from 6 to 127 days (mean $44 \pm 37$ days) with over half having symptoms for more than a month before diagnosis. This is longer than previous studies relying on a retrospective review of medical records ${ }^{25-27}$ but similar to a study which used a checklist to identify subtle symptoms that might otherwise not have been recorded, in which the mean duration in 106 children without DKA was $43.2 \pm 57.1$ days. ${ }^{28}$ These findings suggest that current estimates of the diagnostic delay in children with T1D may underestimate delays to diagnosis.
For almost all families, most of that time was the appraisal interval. As in a study of the parents of children diagnosed with cancer, ${ }^{29}$ parents appeared to categorise early symptoms of diabetes in broadly three ways: those for which alternative explanations were readily available; those that were not of concern and those which concerned them and subsequently prompted help-seeking. The non-specific nature and behavioural elements of the symptoms of T1D led most parents to initially find alternative explanations for the symptoms without considering their child was unwell. Even when they did not have alternative explanations, symptoms that were intermittent, not unusual or were not making the child unwell did not raise concern, while symptoms that were unusual, physical or interfering with daily life prompted help-seeking. This is consistent with previous studies in children ${ }^{30-32}$ and adults ${ }^{33} 34$ and also highlights the central role of the concept of normality 313536 to this distinction between non-concerning and concerning symptoms. This process, however, was not a simple linear one in which progression of symptoms led parents to move from alternative explanations through recognition of non-concerning symptoms to those causing concern. Instead, the process was cyclical and iterative, as described in the model of Pathways to Treatment, ${ }^{23}$ with parents continually reappraising the symptoms and their own interpretations and, in many cases, needing a physical symptom, such as vomiting or weight loss, to trigger help-seeking. The variation in the duration of the appraisal interval appears to reflect parents' differing readiness to accept any deviation from 'normal' in their child.

As previously described, ${ }^{30} 37$ there was evidence that mothers made use of a social network of extended family, friends and work colleagues throughout this process and almost all parents also sought information from the internet. Added to a prior understanding of T1D, the majority had either made the diagnosis themselves or suspected it by the time they contacted a healthcare professional. As in other studies, however, parents did not make the decision to contact a healthcare professional lightly, ${ }^{29} 303839$ and the most common reason for delaying in booking an appointment with a GP was concern about attending with non-specific symptoms and wasting the GP's time. Perhaps the most important finding, however, is that many parents who suspected diabetes were unaware of the potential seriousness of the condition and decisions about seeking help were framed by their understanding of type 2 diabetes and information from the internet, which seemingly failed to emphasise the importance of seeking medical help early in children.

The diagnostic interval was the shortest period for all children. In contrast to other studies, ${ }^{39} 40$ getting access to healthcare professionals was generally not a barrier for families. Parents did, however, describe how many GPs seemed reluctant to consider T1D or initiate testing and, as in a study of the perceptions of parenting 
children with $\mathrm{T}^{4} \mathrm{D}^{41}$ and studies of children diagnosed with cancer ${ }^{29}$ and minor illness, ${ }^{30}$ parents felt that their views were not respected and concerns not taken seriously. The reluctance to perform point of care tests was also seen in GP accounts where GPs described time pressures and concern about causing distress to children. In all consultations in which either the parents or healthcare professional had considered T1D, however, point of care tests were performed and the child appropriately referred to secondary care. In the two cases not diagnosed at the first encounter with a GP, both had been asked to bring a urine sample into the practice the following day and there was no evidence that this delay was harmful. Any perceived lack of knowledge or understanding on the part of GPs did not, therefore, appear to affect the care the children received.

\section{Implications for clinicians and policymakers}

Overall, this study highlights the variability in the pathway to diagnosis of T1D in children and the difficulties parents and healthcare professionals face in interpreting the early symptoms. Taken together, the findings have a number of implications for frontline clinicians as well as policymakers supporting research and designing future interventions to improve the pathway to diagnosis of this and other childhood conditions. First, most of the total diagnostic interval for T1D in children is the appraisal interval, and so interventions aimed at improving timely diagnosis need to focus on this interval. Future interventions should therefore be directed towards parents and their social network, and this study suggests that the most effective route would be via the internet. Second, there is currently a lack of appreciation among parents of the potential seriousness of T1D in children and confusion between T1D and type 2 diabetes. Any interventions aimed at parents therefore need to make clear the differences between these and emphasise the importance of timely presentation to a healthcare professional.

Third, and perhaps the key message for clinicians, is the importance of trusting parental concern. Parents are the main advocate (and in some cases the barrier) to seeking appropriate care for their child. They do not make help-seeking decisions lightly and go through complex appraisal processes which include researching on the internet, using social networks, contacting expert friends and even doing tests themselves. By the time they present to healthcare professionals, they are therefore not only experts on what is normal for their child, but also often in a position to prompt or persuade healthcare professionals to do tests that they might otherwise not have considered. As with other serious illnesses in children, ${ }^{42}$ listening to parents and trusting parental concern is, therefore, key to the diagnosis of T1D.

Finally, this study confirms the challenges that parents and clinicians face with diagnosing serious illnesses in children due to early non-specific presentations.
Moreover, with a few notable exceptions, such as with the recent revision of clinical guidelines around meningitis using primary care derived evidence, ${ }^{43}$ there is typically little evidence for the early diagnostic features of most such illnesses. Unlike common conditions, where primary care physicians learn experientially, for rare conditions such as T1D in children where, for example, the average GP working in the UK will only make the diagnosis once or twice in a career, that learning is unlikely to take place within practice and specific educational programmes may be valuable. Even when neither the parents nor the GPs had thought specifically of T1D, however, the diagnostic interval was short and most diagnoses were made promptly as a result of urine tests requested as part of the assessment of a non-specifically unwell child. It is not clear, therefore, whether T1D-specific educational interventions aimed at primary care physicians in particular would necessarily have much impact on the pathway to diagnosis. Instead, the message to primary care physicians and nurses and health visitors providing first-line care from this study is to consider T1D in non-specifically unwell children and perform a dipstick test on urine during the consultation for all children with polyuria, polydipsia, nocturia or weight loss.

\section{Unanswered questions and future research}

Although this study provides an in-depth exploration of the pathway to diagnosis and should inform the development of future interventions aimed at reducing the severity of disease at presentation of T1D in children, the findings need to be confirmed. In particular, there are still major gaps in our understanding of the diagnostic pathway and the best approaches for future interventions. There are no large studies describing the symptoms and presentation of children with T1D in primary care; while it seems intuitive that increasing knowledge of individual conditions would improve recognition and diagnosis, the extent to which parental or primary care physician prior knowledge of T1D contributes to the duration of symptoms and severity of disease at presentation is not clear. More generally, this study also highlights the difficulties that can arise when translating knowledge of disease presentations from secondary care to primary care, as well as the need for continuing research into the presentation of rare conditions in primary care.

Acknowledgements The authors would like to thank all the parents and children and GPs who kindly gave up their time and shared their personal stories with us and the paediatric diabetes clinical teams at the two hospitals, They also acknowledge the support of the National Institute for Health Research, through the Primary Care Research Network, particularly Brenda Deboys at the East of England Primary Care Research Network and Lesley Maloney at the Suffolk Primary Care Research Network for help with recruitment. They are also grateful to the Diabetes Research Network for research support, James Brimicombe for advice on data management and for developing the research database and Professor David Dunger for his support and encouragement throughout the study and comments on the final manuscript. 
Contributors All authors were involved in the design of the study and analysis of the data. JAU-S performed all the interviews and wrote the first draft of the manuscript. FMW and MJT reviewed and edited the manuscript.

Funding The study was funded by the Royal College of General Practitioners Scientific Foundation Board (SFB-2011-15). Service support costs were also provided by the Cambridgeshire and Norfolk and Suffolk Comprehensive Local Research Networks. JAU-S was supported by an NIHR Academic Clinical Fellowship, FMW by an NIHR Clinical Lectureship at the time of this study and this report includes independent research arising from MJT's Career Development Fellowship supported by the National Institute for Health Research. The views expressed in this publication are those of the author(s) and not necessarily those of the NHS, the National Institute for Health Research or the Department of Health.

Competing interests None.

Ethics approval The study obtained ethical approval from the Cambridge South REC (reference number 11/EE/0435).

Provenance and peer review Not commissioned; externally peer reviewed. Data sharing statement No additional data are available.

Open Access This is an Open Access article distributed in accordance with the Creative Commons Attribution Non Commercial (CC BY-NC 3.0) license, which permits others to distribute, remix, adapt, build upon this work noncommercially, and license their derivative works on different terms, provided the original work is properly cited and the use is non-commercial. See: http:// creativecommons.org/licenses/by-nc/3.0/

\section{REFERENCES}

1. DIAMOND Project Group. Incidence and trends of childhood type 1 diabetes worldwide 1990-1999. Diabet Med 2006;23:857-66.

2. EURODIAB ACE Study. Variation and trends in incidence of childhood diabetes in Europe. Lancet 2000;355:873-6.

3. Ali K, Harnden A, Edge JA. Type 1 diabetes in children. BMJ 2011;342:d294.

4. Blanc N, Lucidarme N, Tubiana-Rufi N. Factors associated to ketoacidosis at diagnosis of type 1 diabetes in children. Arch Pediatr 2003;10:320-5.

5. Hamilton DV, Mundia SS, Lister JC. Mode of presentation of juvenile diabetes. BMJ 1976;2:211-12.

6. Mallare JT, Cordice CC, Ryan BA, et al. Identifying risk factors for the development of diabetic ketoacidosis in new onset type 1 diabetes mellitus. Clin Pediatr 2003;42:591-7.

7. Pawłowicz M, Birkholz D, Niedźwiecki M, et al. Difficulties or mistakes in diagnosing type 1 diabetes mellitus in children? The consequences of delayed diagnosis. Endokrynol Diabetol Chor Przemiany Materii Wieku Rozw 2008;14:7-12.

8. Soliman AT, EIZalabany MM, Bappal B, et al. Permanent neonatal diabetes mellitus: epidemiology, mode of presentation, pathogenesis and growth. Indian J Pediatr 1999;66:363-73.

9. Usher-Smith JA, Thompson M, Ercole A, et al. Variation between countries in the frequency of diabetic ketoacidosis at first presentation of type 1 diabetes in children: a systematic review. Diabetologia 2012;55:2878-94.

10. Rewers A, Brown A, Rewers M. Diabetic ketoacidosis at diagnosis predicts poorer glycemic control in the initial course of type 1 diabetes. Abstract presented at the Pediatric Society Meeting; Toronto, Canada.

11. Bowden SA, Duck MM, Hoffman RP. Young children ( $<5 \mathrm{yr}$ ) and adolescents ( $>12 \mathrm{yr}$ ) with type 1 diabetes mellitus have low rate of partial remission: diabetic ketoacidosis is an important risk factor. Pediatr Diabetes 2008;9:197-201.

12. Abdul-Rasoul M, Habib H, Al-Khouly M. "The honeymoon phase" in children with type 1 diabetes mellitus: frequency, duration, and influential factors. Pediatr Diabetes 2006;7:101-7.

13. International Diabetes Federation. Defeat DKA and Save Lives. http://www.idf.org/worlddiabetesday/dka (accessed 13 Aug 2013).

14. Vanelli M, Chiari G, Ghizzoni L, et al. Effectiveness of a prevention program for diabetic ketoacidosis in children. An 8-year study in schools and private practices. Diabetes Care 1999;22:7-9.

15. Diabetes UK. 4 Ts campaign. http://www.diabetes.org.uk/Get involved/Campaigning/4Ts-campaign/ (accessed 13 Aug 2013).

16. Dasman Diabetes Institute. Diabetic ketoacidosis prevention awareness campaign. http://www.dasmaninstitute.org/fr/news/ diabetic-ketoacidosis-dka-prevention-awareness-campaignal-kout-mall (accessed 13 Aug 2013).

17. King BR, Howard NJ, Verge CF, et al. A diabetes awareness campaign prevents diabetic ketoacidosis in children at their initia presentation with type 1 diabetes. Pediatr Diabetes 2012;13:647-51.

18. Diabetes Foundation of Mississippi. You're never too young to have diabetes. http://www.msdiabetes.org/article.php?article_id=71 (accessed 13 Aug 2013).

19. Usher-Smith JA, Thompson MJ, Sharp SJ, et al. Factors associated with the presence of diabetic ketoacidosis at diagnosis of diabetes in children and young adults: a systematic review. Br Med J 2011;343:d4092.

20. Youthhealthtalk.org. http://www.youthhealthtalk.org/Diabetes_type 1_in_young_people/Topic/1510.

21. Glasner T, van der Vaart W. Applications of calendar instruments in social surveys: a review. Qual Quantity 2009;43:333-49.

22. Braun V, Clarke V. Using thematic analysis in psychology. Qual Res Psychol 2006;3:77-101.

23. Walter F, Webster A, Scott S, et al. The Andersen Model of Tota Patient Delay: a systematic review of its application in cancer diagnosis. J Health Serv Res Policy 2012;17:110-18.

24. Scott SE, Walter FM, Webster A, et al. The model of pathways to treatment: conceptualization and integration with existing theory. $\mathrm{Br} J$ Health Psychol 2013;18:45-65.

25. Neu A, Willasch A, Ehehalt S, et al. Ketoacidosis at onset of type diabetes mellitus in children-frequency and clinical presentation. Pediatr Diabetes 2003;4:77-81.

26. Kapellen TM, Galler A, Nietzschmann U, et al. Prevalence of diabetic ketoacidosis in newly diagnosed children and adolescents with type 1 diabetes mellitus. Experience of a center for pediatric diabetology in Germany. [Article in German]. Monatsschrift fur Kinderheilkunde 2001;149:679-82.

27. Samuelsson U, Stenhammar L. Clinical characteristics at onset of type 1 diabetes in children diagnosed between 1977 and 2001 in the south-east region of Sweden. Diabetes Res Clin Pract 2005;68:49-55.

28. Ting WH, Huang CY, Lo FS, et al. Clinical and laboratory characteristics of type 1 diabetes in children and adolescents: experience from a medical center. Acta Paediatr Taiwan 2007;48:119-24.

29. Dixon-Woods M, Findlay M, Young B, et al. Parents' accounts of obtaining a diagnosis of childhood cancer. Lancet 2001;357:670-4.

30. Neill SJ. Acute childhood illness at home: the parents' perspective. J Adv Nurs 2000;31:821-32.

31. Irvine S, Cunningham-Burley S. Mothers' concepts of normality, behavioural change and illness in their children. Br J Gen Pract 1991;41:371-4.

32. Cornford CS, Morgan M, Ridsdale L. Why do mothers consult when their children cough? Fam Pract 1993;10:193-6.

33. Macleod U, Mitchell ED, Burgess C, et al. Risk factors for delayed presentation and referral of symptomatic cancer: evidence for common cancers. Br J Cancer 2009;101:S92-101.

34. Smith LK, Pope C, Botha JL. Patients' help-seeking experiences and delay in cancer presentation: a qualitative synthesis. Lancet 2005;366:825-31.

35. Cunningham-burley $S$, Irvine S. "And have you done anything so far?" An examination of lay treatment of children's symptoms. BMJ 1987;295:700-2.

36. Hopton J, Hogg R, McKee I. Patients' accounts of calling the doctor out of hours: qualitative study in one general practice. BMJ 1996;313:991-4.

37. Kai J. Parents' difficulties and information needs in coping with acute illness in preschool children: a qualitative study. BMJ 1996;313:987-90.

38. Houston AM, Pickering AJ. "Do I don't I call the doctor": a qualitative study of parental perceptions of calling the GP out-of-hours. Health Expect 2000;3:234-42.

39. Francis NA, Crocker JC, Gamper A, et al. Missed opportunities for earlier treatment? A qualitative interview study with parents of children admitted to hospital with serious respiratory tract infections. Arch Dis Child 2011;96:154-9.

40. Crocker JC, Evans MR, Powell CVE, et al. Why some children hospitalized for pneumonia do not consult with a general practitioner before the day of hospitalization. Eur J Gen Pract 2013;19:213-20.

41. Smaldone A, Ritholz MD. Perceptions of parenting children with type 1 diabetes diagnosed in early childhood. J Pediatr Health Care 2011;25:87-95.

42. Van den Bruel A, Aertgeerts B, Bruyninckx R, et al. Signs and symptoms for diagnosis of serious infections in children: a prospective study in primary care. Br J Gen Pract 2007;57:538-46.

43. National Institute for Health and Care Excellence. The management of bacterial meningitis and meningococcal septicaemia in children and young people younger than 16 years in primary and secondary care. 2010. 